\title{
Fusarium Hardlock Associated With Lygus lineolaris (Hemiptera: Miridae) Injury in Southeastern Cotton
}

\author{
Seth J. Dorman, ${ }^{\dagger}$ Joseph Opoku, Hillary L. Mehl, and Sally V. Taylor \\ Tidewater Agricultural Research and Extension Center, Virginia Tech University, Suffolk, VA 23437
}

\begin{abstract}
The tarnished plant bug, Lygus lineolaris (Palisot de Beauvois), is an important insect pest in cotton that feeds on reproductive fruit, contributing to yield loss. Economically damaging infestations of $L$. lineolaris have doubled in Virginia since 2013. Escalation of L. lineolaris abundance may increase Fusarium hardlock disease observed in this region, compounding economic losses. Research has linked Fusarium hardlock with fungal species Fusarium verticillioides and $F$. proliferatum. Field and greenhouse experiments were performed to investigate (i) Fusarium hardlock occurrence in field plots managed and unmanaged for $L$. lineolaris, (ii) severity of $F$. verticillioides infection of cotton bolls with and without the presence of $L$. lineolaris feeding in a greenhouse setting, and (iii) Fusarium species com-

occurred in field-collected bolls with $L$. lineolaris feeding symptoms $(0.40 \pm$ $0.02)$ compared with bolls without $(0.21 \pm 0.01)$. Based on real-time quantitative PCR, cotton bolls exposed to $F$. verticillioides inoculum and caged with $L$. lineolaris adults had greater levels of $F$. verticillioides DNA compared with untreated bolls. $F$. proliferatum, $F$. verticillioides, and $F$. fujikuroi were isolated from field-collected $L$. lineolaris and hardlocked cotton lint at harvest. These findings suggest that the presence of L. lineolaris is associated with an increased risk of Fusarium hardlock in Southeastern cotton, and both should be carefully managed using timely insecticide applications and cultural control practices to minimize yield loss.
\end{abstract} position and prevalence within field-collected $L$. lineolaris and cotton lint with and without insect feeding injury and hardlock symptoms present. Nearly twice the amount of hardlock (i.e., proportion of hardlocked locules)
Keywords: Fusarium hardlock, Gossypium hirsutum L., insect-pathogen interactions, tarnished plant bug
Cotton (Gossypium hirsutum L.) boll rot diseases caused by bacterial and fungal pathogens proliferate under humid conditions in the southeastern United States (Lawrence et al. 2019). Fusarium hardlock (hereafter, "hardlock"), a disease often associated with the boll rot disease complex, has been attributed to substantial losses in harvestable lint yield (up to $70 \%$ ) in cotton production systems in this region (Wright et al. 2004). Hardlock symptoms are characterized by the contraction and stiffening of lint fibers in mature cotton fruit that do not expand upon boll opening, thereby remaining unharvestable with a mechanical spindle picker (Mailhot et al. 2007; Srivastava et al. 2010). Less apparent symptoms may include reduced seed weight and abnormal fiber configuration (Srivastava et al. 2010). The prevalence and severity of hardlock has been associated with various factors, including high humidity and temperature, nitrogen rates, and heavy rainfall (Wright et al. 2004). The association between cotton boll rotting diseases, including hardlock, and piercing-sucking heteropterans is also well documented (Bagga and Laster 1968; Mailhot et al. 2007; Mitchell 2004). Moreover, the majority of heteropteran associations with fungal pathogens specifically consist of insects within the Miroidea and Pentatomoidea superfamilies ( $>65$ associations) (Mitchell 2004). These insect groups have thicker mouthparts or stylets compared with other common insect vectors (e.g., Aphididae, Thripidae) in field crop systems, creating more extensive wounds for pathogen entry, and they feed using saliva with digestive enzymes

${ }^{\dagger}$ Corresponding author: S. J. Dorman; sjdorman@vt.edu

Funding: This work was made possible through funding from Cotton Incorporated, the Virginia Cotton Board, the Virginia State Cotton Support Committee, the Southern IPM Center (SIPMC), and the cooperation and support of Virginia cotton growers. The SIPMC is supported by the U.S. Department of Agriculture National Institute of Food and Agriculture Crop Protection and Pest Management program (award 2018-70006-28884, project accession 1017626).

The author(s) declare no conflict of interest.

Accepted for publication 3 July 2020

(C) 2021 The American Phytopathological Society (i.e., proteases and nucleases), which may aid in pathogen transmission (Cline and Backus 2002; Liu and Bonning 2019; Mitchell 2004). This study describes the relationship between an increasingly problematic insect pest in Southeastern cotton, the tarnished plant bug, Lygus lineolaris (Palisot de Beauvois), and hardlock disease in this region.

L. lineolaris is a highly polyphagous sap feeder with $>300$ documented hosts and a preference for flowering broadleaf weeds (e.g., Asteraceae) (Fleischer and Gaylor 1988; Snodgrass et al. 1984; Tugwell et al. 1976; Young 1986). Populations of L. lineolaris are capable of flying long distances (i.e., $12 \mathrm{~km}$ in $12 \mathrm{~h}$ ) and will migrate from wild hosts to cultivated crops (e.g., maize, cotton) when early-season hosts senesce in late spring (Stewart and Gaylor 1994). There is also a predictive migration pattern of $L$. lineolaris from maize to nearby cotton when maize reaches the R2/R3 reproductive growth stage (Dorman et al. 2020; Jackson et al. 2014). L. lineolaris causes economic damage to cotton by feeding on reproductive fruiting structures (i.e., squares, flowers, and small bolls) and vegetative stems, leading to fruit abscission, reduced lint quality, or delayed maturity (Bariola 1969; Hanny et al. 1977; Layton 2000; Tugwell et al. 1976). Lygus insects have also demonstrated prolonged dabbing behavior on mature cotton, creating additional wounds on plants; this behavior may be employed to prepare tissues for digestion or overcome plant defenses (e.g., gossypol) (Cline and Backus 2002). In Midsouthern cotton, L. lineolaris has been a major pest for several decades, which is attributable to reduced insecticide applications targeting lepidopteran and coleopteran pests that resulted from the introduction of transgenic Bacillus thuringiensis cotton and the successful Boll Weevil Eradication Program (Layton 2000; Musser et al. 2007; Williams 2017; Wood et al. 2016). Economically damaging infestations of L. lineolaris in Virginia cotton started in 2013 and have dramatically increased regional insecticide usages, averaging over two applications per hectare annually (Williams 2014, 2017).

The fungal species Fusarium verticillioides has been linked with hardlock and described as the likely causal agent of the disease (Marois and Wright 2004; Marois et al. 2002; Srivastava et al. 2010). $F$. verticillioides can persist in soil residue for long periods, often dispersed by air and wind, and can survive a wide range of temperatures and moisture availabilities (Leslie and Summerell 2006; Sempere and Santamarina 2009). The F. verticillioides growth rate for maize, 
a well-documented host of $F$. verticillioides, and other host species is typically maximized on injured and immature/reproductive tissues (Leslie and Summerell 2006; Opoku et al. 2019; Yates and Jaworski 2000). F. verticillioides can also act as an endophyte, surviving and reproducing inside of plant hosts to avoid competition and secure protection from other fungal species (Leslie and Summerell 2006).

The feeding behavior of $L$. lineolaris and the migration pattern from maize to cotton, in addition to $F$. verticillioides biology as an endophyte and its ubiquitous nature in field crop systems, may result in the increased development of $F$. verticillioides in cotton fruit and prevalence of hardlock at boll opening. Moreover, if L. lineolaris density correlates with hardlock prevalence, higher L. lineolaris infestations in the Southeast may lead to a greater incidence of hardlock when insect infestations coincide with optimal environmental conditions conducive to hardlock disease (i.e., moist and warm climate). Previous work by Bagga and Laster (1968) showed potential for field-collected $L$. lineolaris in Mississippi to initiate boll rot symptoms; incidence of boll rot was similar for field-collected $L$. lineolaris and field-collected $L$. lineolaris exposed to $F$. moniliforme (split into several species, including $F$. verticillioides; Seifert et al. 2003) for 24 h. Work by Mailhot et al. (2007) demonstrated the ability of flower thrips (Frankliniella spp.) alone, and in combination with Fusarium species, to increase hardlock symptoms above untreated control treatments in the Southeast. To better understand the potential relationship between $L$. lineolaris feeding on cotton fruit and occurrence of hardlock in Virginia, we designed multiple experiments (i) to calculate the proportion of hardlocked locules and insect-damaged bolls in managed and unmanaged field plots, (ii) to investigate the severity of $F$. verticillioides infection of cotton fruit (i.e., small fruit) with and without the presence of $L$. lineolaris feeding in a greenhouse setting, and (iii) to determine Fusarium species associated with $L$. lineolaris populations and cotton bolls in field cotton.

\section{Materials and Methods}

Field assessment of hardlock and $\boldsymbol{L}$. lineolaris feeding. To determine the prevalence of hardlock and L. lineolaris injury in cotton bolls, field experiments were conducted at the Tidewater Agricultural Research and Extension Center in Suffolk, Virginia, from 2016 to 2018. Cotton was planted in early May each year with variety DP 1538 B2XF in 2016 and 2017; because of limited availability, similar variety DP 1840 B3XF was planted in 2018. Two treatments were arranged in a randomized complete block design with four replicates in 2016 and eight replicates in 2017 and 2018. Plots were eight rows wide by $12 \mathrm{~m}$ long (0.9-m row spacing) with approximately 10 seeds planted per row meter. Treatments consisted of an untreated control and insect management treatment. The insect management treatment was scouted weekly for $L$. lineolaris using sweep net (prebloom) and black drop cloth sampling (postbloom); plots were sprayed with Brigrade (bifenthrin, $0.11 \mathrm{~kg}$ of active ingredient [a.i.]/ha; FMC, Philadelphia, PA) and Orthene (acephate, $0.55 \mathrm{~kg}$ of a.i./ha; AMVAC, Newport Beach, CA) when Virginia Tech University Extensionrecommended thresholds were reached (prebloom: eight $L$. lineolaris per 100 sweeps; postbloom: 2.5 L. lineolaris per 1.5 row meters) until physiological maturity was determined by five nodes above the white flower plus 350 heat units (Aghaee et al. 2019; Musser et al. 2007; Wood et al. 2016). To suppress corn earworm (Helicoverpa zea) populations, Prevathon (chlorantraniliprole, $0.07 \mathrm{~kg}$ of a.i./ha; FMC) was applied to fields prophylactically each year. Plots were maintained throughout the growing season following Virginia Cooperative Extension agronomic recommendations (Frame et al. 2016).

Cotton bolls were assessed for insect feeding and hardlock symptoms 2 weeks after defoliant applications (Mailhot et al. 2007). All bolls on five consecutive plants were analyzed within each plot; bolls in border rows 1 and 8 were excluded. Individual bolls were categorized as insect "feeding present" if at least one locule displayed internal injury characteristic of L. lineolaris feeding, including stained lint, clear raised warts, and/or black punctures on the inner carpel wall (Blinka et al. 2010; Willrich et al. 2004). The proportion of locules with hardlock was recorded for each boll, which included locules displaying characteristic hardlock symptoms (e.g., contraction and stiffening of lint fibers) and deemed unharvestable with a mechanical spindle picker (Mailhot et al. 2007; Srivastava et al. 2010).

Greenhouse experiment. To investigate the relationship between L. lineolaris feeding and Fusarium hardlock incidence in cotton, plants were grown in a closed greenhouse at the Tidewater Agricultural Research and Extension Center in Suffolk, Virginia, and exposed to $L$. lineolaris adults in the presence and absence of $F$. verticillioides during the cotton growing season (i.e., April to September). Cotton variety DP $1538 \mathrm{~B} 2 \mathrm{XF}$ was planted in 11-liter pots with potting soil mix and $8 \mathrm{~g}$ of Osmocote 14-14-14 fertilizer (ScottsMiracle-Gro, Marysville, $\mathrm{OH}$ ). Plants were watered twice daily using drip irrigation, and Mepex growth regulator (mepiquat chloride; Nufarm, Melbourne, Australia) was applied to each plant twice to slow development. Plants were treated with $0.17 \mathrm{ml}$ of Admire Pro (imidacloprid; Bayer CropScience, Durham, NC) after germination to reduce nontarget insect feeding (e.g., thrips, whiteflies, aphids). Six treatments were arranged in a randomized complete block design with four blocks and three replicates (of each treatment) per block. Treatments included (i) bolls exposed to two fieldcollected $L$. lineolaris adults for 5 days, (ii) bolls inoculated with $F$. verticillioides, (iii) bolls mechanically punctured with a sterilized 0.1-mm needle ( $2 \mathrm{~mm}$ in length; Esquivel 2015) to mimic L. lineolaris feeding (20 punctures per boll), (iv) a combination of treatments 1 and 2, (v) a combination of treatments 2 and 3, and (vi) an untreated control. Two observations (i.e., cotton bolls) were nested within each experimental unit (i.e., individual plant). Each treatment combination was replicated at least 24 times on 12 total plants in 2017 and 2018 (i.e., 48 total replicates per treatment across both years). Four tables, positioned in different locations throughout the greenhouse, served as blocks for each replicate to account for potential environmental variability and insect outbreaks. All treatments were administered when bolls accumulated between 56 and 111 degree days (DDs) calculated by subtracting the average of daily maximum and minimum temperatures by a base threshold of $15.6^{\circ} \mathrm{C}$; this is when bolls are most susceptible to L. lineolaris feeding (Horn et al. 1999). Greenhouse temperature and percent $\mathrm{RH}$ were recorded in 15-min intervals using a centrally located HOBO MX2300 data logger (ONSET, Bourne, MA). The average temperature (in degrees Celsius) and percent RH across both years was $26.9 \pm 3.4 \mathrm{SD}$ and $82.5 \pm 12.2 \mathrm{SD}$, respectively. Reproductive nodes were tagged with the date of anthesis (i.e., white flower) to monitor DD accumulation and treatment timing. The diameter of bolls at treatment introduction was also measured using a vernier caliper to the nearest tenth of a millimeter to ensure that bolls used were uniform in size and development. Small nylon mesh cages $(20 \times 25 \mathrm{~cm})$ were placed over 24 bolls within the appropriate DD range for each treatment combination and secured using a drawstring. As expected, the stress of treatments on small fruiting structures resulted in premature boll abscission, lowering the total number of replicates per treatment. Caged bolls that abscised prematurely were replaced as needed until six total bolls had been treated per plant, with only two caged bolls per plant at any given time. Cages with $L$. lineolaris were checked daily for mortality and replaced if necessary. Cages were placed on all treated bolls to standardize environmental variation among treatments.

L. lineolaris adults were collected from wild hosts within 1 week of introductions. Adults were held in nylon mesh cages $(33 \times 33 \times$ $33 \mathrm{~cm}$ ) and fed a diet of organic green beans purchased locally and sanitized using protocols outlined in Snodgrass (1996). An F. verticillioides isolate was transferred and grown on one-quarter-strength potato dextrose agar (PDA) plates $(9.75 \mathrm{~g} / \mathrm{liter})$. After 2 weeks, conidia were rinsed from the plates using a diluted $0.01 \%$ Tween 20 solution (Sigma, St. Louis, MO) with sterilized deionized water to create a 9 to $33 \times 10^{5}$ conidia/ml suspension (Mailhot et al. 2007). Approximately $5 \mathrm{ml}$ of the $F$. verticillioides suspension was sprayed on designated bolls at the time cages were installed in the presence or absence of L. lineolaris. After the 5-day exposure period had concluded, adults were removed from cages. Cages were placed back on the bolls, and the bolls were harvested once they had accumulated between 556 to $611 \mathrm{DD}$, just before boll opening, to reduce cotton lint exposure to potential pathogens in the greenhouse. Bolls were 
hand harvested and assessed for L. lineolaris feeding symptoms (e.g., stained lint, clear raised warts, and/or black punctures). To account for the inherent mismatch in harvested bolls per treatment due to premature boll abscission, a maximum of 15 random bolls for each treatment were selected for analysis each year (i.e., 30 total bolls analyzed per treatment). Bolls were stored at $-20^{\circ} \mathrm{C}$ until DNA analysis.

DNA analysis of greenhouse cotton bolls using quantitative PCR. F. verticillioides DNA in harvested bolls from the greenhouse experiment was quantified using real-time quantitative PCR (qPCR) with $F$. verticillioides-specific primers (Mulè et al. 2004; Opoku et al. 2019). Cotton bolls were opened with a sterile scalpel and lint was removed with sterile forceps; instruments were held over an open flame between samples. All lint from each boll sample was placed in 50-ml tubes with approximately $25 \mathrm{ml}$ of $0.01 \%$ Tween 20 solution (Sigma) with sterile deionized water $\left(\mathrm{ddH}_{2} \mathrm{O}\right)$, vortexed for $60 \mathrm{~s}$, and then removed before centrifugation at 4,500 rpm for $30 \mathrm{~min}$. Liquid wash was discarded and the pellet was resuspended in $1 \mathrm{ml}$ of CLS-Y from the FastDNA SPIN Kit (MP Biomedicals, Solon, OH). Samples were then transferred to lysing matrix tubes and homogenized in a Mini-BeadBeater 24 (Biospec Products, Bartlesville, OK) for $40 \mathrm{~s}$ at $3,000 \mathrm{rpm}$. The remaining DNA isolation steps followed the protocol outlined in the FastDNA SPIN Kit. Sample DNA was eluted with $100 \mu$ of $\mathrm{ddH}_{2} \mathrm{O}$ and then further diluted $10 \times$ with $\mathrm{ddH}_{2} \mathrm{O}$. Each well of the qPCR plate included $5 \mu$ l of Sso Advanced Universal SYBR Green Supermix (Bio-Rad Laboratories, Hercules, CA), $0.25 \mu$ l each of $250 \mathrm{nM}$ forward and reverse $F$. verticillioides-specific primers (Mulè et al. 2004), $1.5 \mu \mathrm{l}$ of $\mathrm{ddH}_{2} \mathrm{O}$, and $3 \mu \mathrm{l}$ of DNA template. The standard curve included 10-fold dilutions of $F$. verticillioides DNA from 6 to $6 \times 10^{-5} \mathrm{ng}$ per reaction. The 2 -ng stock solution for the standard curve was made from a pure culture of $F$. verticillioides quantified using the Qubit 2.0 fluorometer (Thermo Fisher Scientific, Waltham, MA). Three determinants were plated for each standard concentration, DNA sample, and control. An equal number of replicates per treatment were represented on each plate. Annealing temperatures for qPCR were optimized by first running reactions under a temperature gradient $\left(55\right.$ to $\left.65^{\circ} \mathrm{C}\right)$. Optimized protocols were identical to Opoku et al. (2019). Results were cross-examined with melt curve data to ensure accurate primer specificity. Reactions were run on a CFX Connect Real-Time PCR Detection System (Bio-Rad Laboratories), and quantification data, represented as nanograms of DNA per boll by multiplying data by total extracted volume divided by reaction amount, were generated using the manufacturer's software for the real-time PCR system employed (version 3.1; Bio-Rad Laboratories).

DNA analysis of field-collected $\boldsymbol{L}$. lineolaris. In 2018, L. lineolaris adults $(n=50)$ were collected using sweep net sampling in August, when L. lineolaris infestations peak in Virginia, from cotton fields at the Tidewater Agricultural Research and Extension Center. Collections were stored at $-20^{\circ} \mathrm{C}$. Adults were surface sterilized by submerging each sample in a $10 \%$ commercial bleach solution for 1 min. Samples were then air-dried and plated on Fusarium-selective media (FSM) (Schmale et al. 2006). Four adults were plated on each dish with at least $2.5-\mathrm{cm}$ spacing. Fungal growth with Fusarium morphology, observed under a compound microscope, was swabbed with a sterile toothpick and placed on full-strength PDA medium ( $39 \mathrm{~g} /$ liter) in Petri plates for a 4-day incubation period $\left(25^{\circ} \mathrm{C}\right)$. A sterile toothpick was used to swab fungal growth on full-strength PDA plates, then mixed with $200 \mu \mathrm{l}$ of $\mathrm{ddH}_{2} \mathrm{O}$ in a 1.5 -ml centrifuge tube, and vortexed. This solution was then pipetted (10 $\mu \mathrm{l})$ onto $2 \%$ water agar plates for a 16 -h incubation period $\left(25^{\circ} \mathrm{C}\right)$. A single germinating conidia spore was transferred to full-strength PDA with sterile Whatman number 1 qualitative filter paper (covering half of the plate) for a 5 -day incubation period $\left(25^{\circ} \mathrm{C}\right)$. Filter papers (with fungal growth) were dried at $50^{\circ} \mathrm{C}$ for $48 \mathrm{~h}$ and permanently stored in sterile envelopes at $-20^{\circ} \mathrm{C}$ to serve as backup specimens if needed. Pure cultures from PDA plates were transferred to lysing matrix tubes with $1 \mathrm{ml}$ of CLS-Y and homogenized using a bead beater for $40 \mathrm{~s}$ at $3,000 \mathrm{rpm}$. Remaining steps for DNA isolation followed the protocol outlined in the FastDNA SPIN Kit. Sample DNA was eluted with $100 \mu \mathrm{l}$ of $\mathrm{ddH}_{2} \mathrm{O}$ and further diluted $10 \times$ in $\mathrm{ddH}_{2} \mathrm{O}$.

The translation elongation factor- $\alpha$ (TEF1- $\alpha$ ) gene was amplified using HotStart PCR Pre-Mix (Bioneer Inc., Alameda, CA) with reaction mixtures of $0.4 \mu \mathrm{l}(0.2 \mu \mathrm{M})$ of forward and reverse primers (elongation factors EF1 and EF2; O'Donnell et al. 1998), $18.2 \mu \mathrm{l}$ of $\mathrm{ddH}_{2} \mathrm{O}$, and $1 \mu \mathrm{l}$ of diluted DNA template (total volume of $20 \mu \mathrm{l})$. A Bio-Rad T100 thermocycler was used for PCR using the protocol outlined in Opoku et al. (2019). Amplicons were then run on a $1.5 \%$ agarose gel consisting of $1 \times$ Tris/Borate/EDTA buffer and gel red fluorescent dye for $1 \mathrm{~h}$ at $90 \mathrm{mV}$. Gels were photographed under ultraviolet light using the Gel Doc XR system (Bio-Rad Laboratories), and $5 \mu \mathrm{l}$ of amplified samples was purified further with the ExoSap-IT kit (Affymetrix Inc., Santa Clara, CA). Purified amplicons were submitted to Eton Bioscience Inc. (Durham, NC) for forward and reverse sequencing. Sequencing results were combined for each sample to form a consensus sequence using Geneious Prime software (version 8.3); species identification was confirmed with a BLAST search on the NCBI database. Sequences were deposited to GenBank (accession numbers MT095057 to MT095059).

Additional L. lineolaris adult collections $(n=300)$ were made in August 2019 from cotton fields at the Tidewater Agricultural Research and Extension Center. Collections were stored at $-20^{\circ} \mathrm{C}$ until DNA analysis. Adults were plated on FSM as described earlier. Fungal growth with Fusarium morphology was swabbed with a sterile toothpick and placed directly in lysing matrix tubes with $1 \mathrm{ml}$ of CLS-Y. DNA was isolated following the protocol described above. Sample DNA was eluted in $\mathrm{ddH}_{2} \mathrm{O}$ with a total volume of $100 \mu \mathrm{l}$ and further diluted $10 \times$ in $\mathrm{ddH}_{2} \mathrm{O}$. TEF1- $\alpha$ was amplified in all DNA samples using the PCR protocol described above. DNA samples with TEF1- $\alpha$ present were also independently amplified with species-specific primers identified in the 2018 sequencing results, including primers specific for $F$. verticillioides (Mulè et al. 2004), $F$. fujikuroi (Amatulli et al. 2012), and $F$. proliferatum (Amatulli et al. 2012). The PCR protocol for each species was optimized using a temperature gradient $\left(55\right.$ to $\left.65^{\circ} \mathrm{C}\right)$ and consisted of initial denaturation of $94^{\circ} \mathrm{C}$ for $5 \mathrm{~min}$, followed by 37 cycles of $94^{\circ} \mathrm{C}$ for $30 \mathrm{~s}, 63^{\circ} \mathrm{C}$ for $1 \mathrm{~min}\left(62^{\circ} \mathrm{C}\right.$ for $F$. verticillioides only), and $72^{\circ} \mathrm{C}$ for $1 \mathrm{~min}$, with a final extension of $72^{\circ} \mathrm{C}$ for $7 \mathrm{~min}$. Gel electrophoresis and amplicon visualization steps were identical to the PCR procedures described above.

DNA analysis of field-harvested cotton using qPCR. In 2018 and 2019, approximately 200 cotton bolls were hand harvested in the same cotton fields used for $L$. lineolaris collections. Bolls were grouped into one of the following categories: (i) L. lineolaris feeding and hardlock symptoms present, (ii) hardlock symptoms only, (iii) $L$. lineolaris feeding symptoms only, or (iv) healthy to serve as a control. L. lineolaris feeding and Fusarium hardlock symptoms were evaluated as described above. Forty representative locules (only one locule per boll) of each category were bagged individually in plastic bags and stored at $-20^{\circ} \mathrm{C}$. Locules were placed in 50-ml tubes with approximately $25 \mathrm{ml}$ of $0.01 \%$ Tween 20 solution (Sigma) with $\mathrm{ddH}_{2} \mathrm{O}$ and centrifuged at 4,500 rpm for $30 \mathrm{~min}$. DNA preparation and isolation procedures were identical to the cotton lint protocol described above. Sample DNA was eluted to reach a final volume of $100 \mu \mathrm{l}$ and further diluted $10 \times$ in $\mathrm{ddH}_{2} \mathrm{O}$. Species-specific primers of $F$. verticillioides (Mulè et al. 2004), $F$. fujikuroi (Amatulli et al. 2012), and $F$. proliferatum (Amatulli et al. 2012) were used to quantify the amount of respective DNA of each species in lint samples using the real-time qPCR preparation steps and reaction mixtures described above. Standard DNA for $F$. fujikuroi and $F$. proliferatum was developed from pure cultures and diluted with $\mathrm{ddH}_{2} \mathrm{O}(2 \mathrm{ng})$ following the methodology for the $F$. verticillioides standard described above. The qPCR protocol included initial denaturation at $98^{\circ} \mathrm{C}$ for $3 \mathrm{~min}, 40$ cycles of $98^{\circ} \mathrm{C}$ for $15 \mathrm{~s}$ and $63^{\circ} \mathrm{C}$ for $2 \min \left(62^{\circ} \mathrm{C}\right.$ for $F$. verticillioides only), and a melt curve run from $65^{\circ} \mathrm{C}$ to $95^{\circ} \mathrm{C}$ in increments of $0.5^{\circ} \mathrm{C}$ for $5 \mathrm{~s}$. Real-time qPCR results were interpreted and analyzed as described above.

Statistical analyses. All results were analyzed using linear mixedeffects models (LMMs) performed using the lme4 (Bates et al. 2015) 
and emmeans (Lenth 2018) packages in R software (version 3.4.3, 2018; R Core Team, Vienna, Austria). The proportion of hardlock observed in field experiments was fitted to a binomial distribution and analyzed using generalized linear mixed-effects models (GLMMs), with insect feeding and management factors as fixed effects and random effects intercepts for plot nested within year. Quantities of Fusarium DNA detected from cotton bolls/locules were log transformed, fitted to a Gaussian distribution, and analyzed using LMMs. For greenhouse samples, model specifications included treatment as fixed effects and random effects intercepts for year and boll nested within plant replicate. For field-collected samples, model specifications included treatment (i.e., hardlock and feeding, feeding only, hardlock only, and control) as fixed effects and random effects intercepts for year. To confirm similarity in boll diameter for bolls selected for greenhouse treatments, boll diameter was fitted to a Poisson distribution and analyzed using a GLMM with replicate as fixed effects and random intercepts for year. The emmeans package was used to contrast differences between treatments using estimated marginal means (EMMs). The Tukey method was then used to compare EMMs $P$ values with a significance level of alpha $=0.05$. DNA quantities represented in the figures were back-transformed using the emmeans package. Summary data in this work are presented as the mean \pm SE.

\section{Results}

Field assessment of hardlock and $\boldsymbol{L}$. lineolaris feeding. The number of cotton bolls assessed at harvest for hardlock and $L$. lineolaris symptoms was 207, 608, and 651 in 2016, 2017, and 2018, respectively $(n=1,466)$. The proportion of locules with hardlock symptoms was different among all four observation combinations $\left(\chi^{2}=49.5 ; \mathrm{df}=3 ; P<0.0001\right)$ (Fig. 1). Moreover, hardlock occurrence was significantly higher for bolls with $L$. lineolaris feeding symptoms present $\left(\chi^{2}=43.7 ; \mathrm{df}=1 ; P<0.0001\right)$. Field-collected bolls with $L$. lineolaris feeding symptoms had nearly twice the

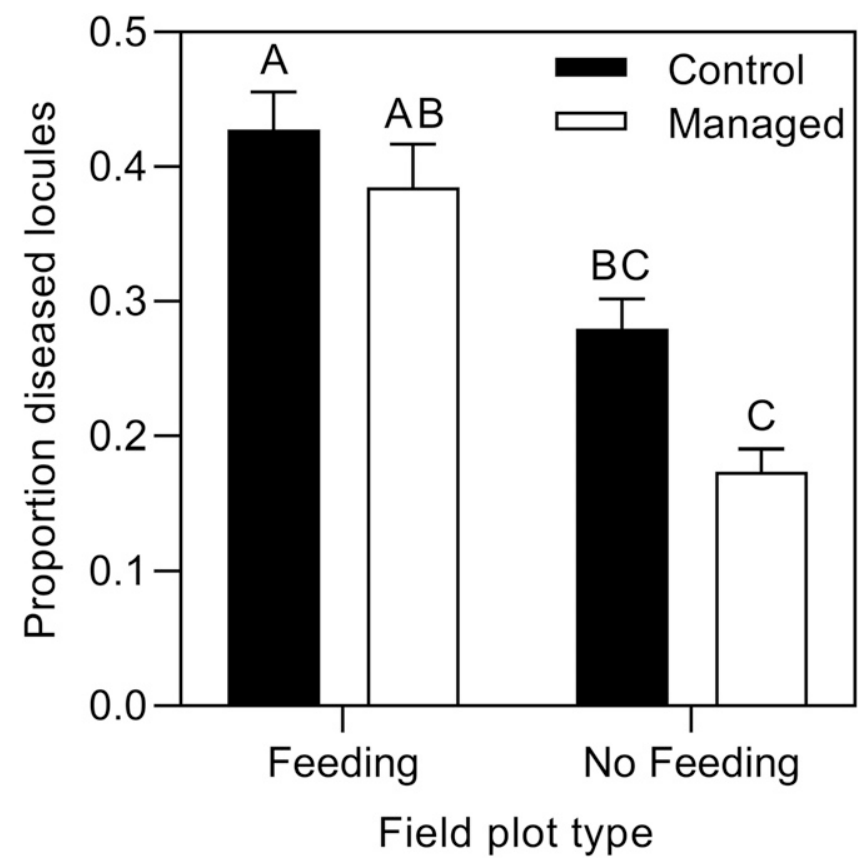

Fig. 1. Proportion of hardlocked locules in cotton bolls $(n=1,466)$ collected from Lygus lineolaris in managed and unmanaged (control) field plots in Suffolk, Virginia, from 2016 to 2018. Managed plots were scouted weekly and sprayed with insecticides when $L$. lineolaris economic thresholds were reached. Bolls were analyzed at harvest and classified as $L$. lineolaris "feeding" or "no feeding" based on internal boll injury symptoms (e.g., stained lint, warts, punctures). The proportion of locules with hardlock were recorded for each boll, including locules displaying characteristic hardlock symptoms (e.g., contraction and stiffening of lint fibers) and deemed unharvestable with a mechanical spindle picker. Means denoted by the same letter were not different based on Tukey's honestly significant difference test $(P<0.05)$. proportion of hardlocked locules $(0.40 \pm 0.02)$ at harvest than bolls with no feeding symptoms $(0.21 \pm 0.01)$. There were no differences in hardlock occurrence observed between managed and unmanaged plots $\left(\chi^{2}=2.15\right.$; df $\left.=1 ; P=0.143\right)$; however, there was a significant interaction between feeding and management factors $\left(\chi^{2}=3.95\right.$; $\mathrm{df}=$ $1 ; P=0.0468)$. Although there were no statistical differences, managed field plots had a numerically lower proportion of hardlocked locules $(0.23 \pm 0.01)$ than unmanaged plots $(0.33 \pm 0.02)$. Furthermore, $L$. lineolaris feeding incidence was nearly half in managed plots $(25.9 \pm 1.7 \%)$ compared with unmanaged plots $(41.0 \pm 2.3 \%)$.

Greenhouse experiment. The majority of cotton bolls subjected to $L$. lineolaris feeding or mechanical punctures had visible feeding symptoms present at harvest $(77.4 \pm 5.3 \%)$; feeding symptoms at harvest were significantly reduced for other treatments $(8.1 \pm 3.2 \%)$. The size of bolls at treatment initiation averaged $12.3 \pm 0.09 \mathrm{~cm}$ and did not vary among treatments $\left(\chi^{2}=6.14 ; \mathrm{df}=6 ; P=0.407\right)$.

The quantity of $F$. verticillioides DNA (in nanograms) differed significantly among treatments $(F=5.50 ;$ df $=5,163.7 ; P<$ $0.0001)$, and treatment response did not vary across years $(F=$ $0.051 ; \mathrm{df}=1,159 ; P=0.822$ ) (Fig. 2). The L. lineolaris with $F$. verticillioides exposure treatment and mechanical puncture with $F$. verticillioides treatment averaged 2.32 and $2.55 \mathrm{ng}$ of Fusarium DNA in cotton bolls, respectively; both of these treatment combinations had significantly greater quantities of $F$. verticillioides DNA compared with noninoculated control bolls. The $F$. verticillioides-only treatment averaged $0.58 \mathrm{ng}$ of DNA and was not different from the untreated control as well as treatments with $F$. verticillioides exposure and feeding injury (i.e., L. lineolaris or mechanical puncture).

DNA analysis of field-collected insects and cotton bolls. Multiple Fusarium species were identified from surface-sterilized field collections of L. lineolaris in $2018(n=50)$ (Fig. 3A). Species confirmed with DNA sequencing included $F$. verticillioides, $F$. fujikuroi, and $F$. proliferatum (GenBank accession numbers MT095057 to MT095059). In 2019, additional $L$. lineolaris field collections $(n=$ 300) were analyzed. Isolated DNA from fungal growth on FSM was amplified using PCR with the Fusarium pathogen (TEF1- $\alpha$ ) and Fusarium species-specific primers, including closely related $F$.

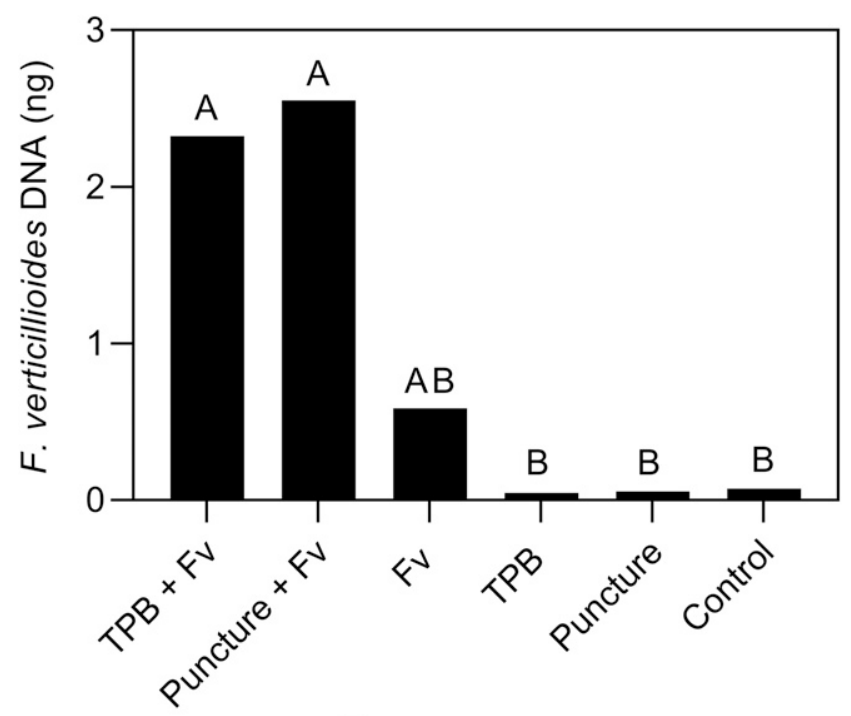

Treatments

Fig. 2. Total Fusarium verticillioides DNA (in nanograms) in cotton bolls using real-time quantitative PCR (qPCR) for six treatments in greenhouse trials in 2017 and 2018. Treatments included (i) Lygus lineolaris feeding and F. verticillioides inoculation (TPB $+\mathrm{Fv} ; n=25)$, (ii) mechanical punctures and $F$. verticillioides inoculation (Puncture $+\mathrm{Fv} ; n=30$ ), (iii) F. verticillioides inoculation only (Fv; $n=30$ ), (iv) $L$. lineolaris only (TPB; $n=26)$, (v) mechanical puncture only (Puncture; $n=30$ ), and (vi) no treatment (Control; $n=30$ ). Bolls were harvested just before boll opening, and real-time qPCR was used to quantify the total amount of $F$. verticillioides DNA in nanograms per boll. Means denoted by the same letter were not different based on Tukey's honestly significant difference test $(P<0.05)$. 
verticillioides, $F$. fujikuroi, and $F$. proliferatum confirmed in L. lineolaris samples the year prior (Fig. 3B). Approximately 4.3, 4.7, and $4.3 \%$ of total samples amplified with $F$. verticillioides, $F$. fujikuroi, and $F$. proliferatum primers, respectively; Fusarium species were not present in $84 \%$ of total samples (i.e., the Fusarium pathogen was not isolated from samples or did not amplify with TEF1- $\alpha$ primers). Of the total samples confirmed to have Fusarium DNA present using the TEF1- $\alpha$ gene $(n=48), F$. verticillioides, $F$. fujikuroi, and $F$. proliferatum species each accounted for approximately 27 to $30 \%$ of Fusarium-positive samples (Fig. 3).

Total Fusarium DNA (in nanograms) detected in field-collected cotton bolls in 2018 and $2019(n=160)$ varied significantly among the four observed symptom categories $(F=3.94$; $\mathrm{df}=3,148.3 ; P=$ 0.0097 ) categorized as (i) L. lineolaris feeding and hardlock, (ii) hardlock only, (iii) L. lineolaris feeding only, or (iv) healthy (Fig. 4). The amount of combined Fusarium DNA for cotton bolls with L. lineolaris feeding and hardlock symptoms, as well as bolls with hardlock symptoms only, differed from healthy bolls (Fig. 4D). The amount of $F$. verticillioides $(F=2.28$; $\mathrm{df}=3,116.2 ; P=$
$0.083)$ and $F$. fujikuroi DNA $(F=1.51 ; \mathrm{df}=3,149 ; P=0.215)$ alone did not vary among categories of observed symptoms, but differences were found for $F$. proliferatum DNA $(F=6.07$; $\mathrm{df}=3$, 146.6; $P=0.0006$ ) (Fig. 4A, B, and C). The amount of $F$. verticillioides DNA was threefold greater in observations with L. lineolaris feeding and hardlock symptoms present $(0.14 \mathrm{ng}) \mathrm{com}-$ pared with bolls with hardlock symptoms only (0.042 ng) (Fig. 4A). The lack of statistical difference may be attributable to variability in qPCR results (i.e., high number of samples with no $F$. verticillioides amplification). Analyzed bolls with both $L$. lineolaris feeding and hardlock symptoms present had the highest amount of Fusarium DNA for all real-time qPCR tests but were not significantly different than hardlock-only bolls.

\section{Discussion}

The presence of $L$. lineolaris feeding injury was associated with the increased incidence of hardlock disease in field experiments. Specifically, the proportion of hardlocked locules was nearly double when $L$. lineolaris feeding occurred. This result suggests that $L$.
A

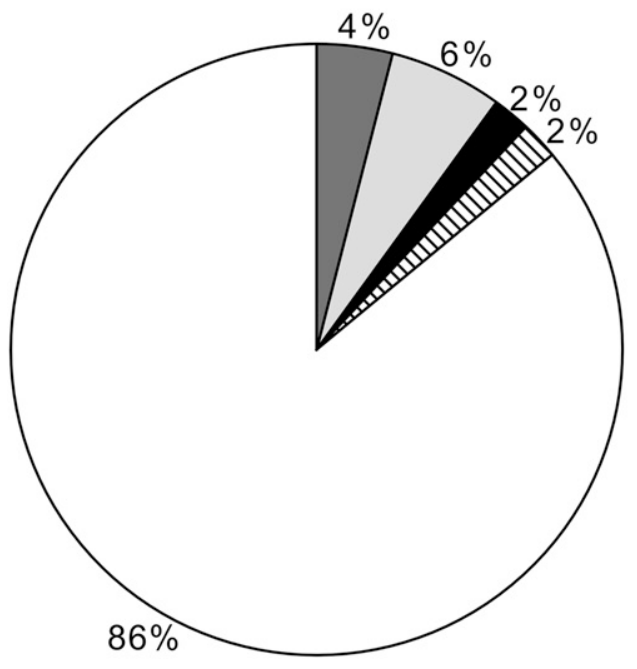

B

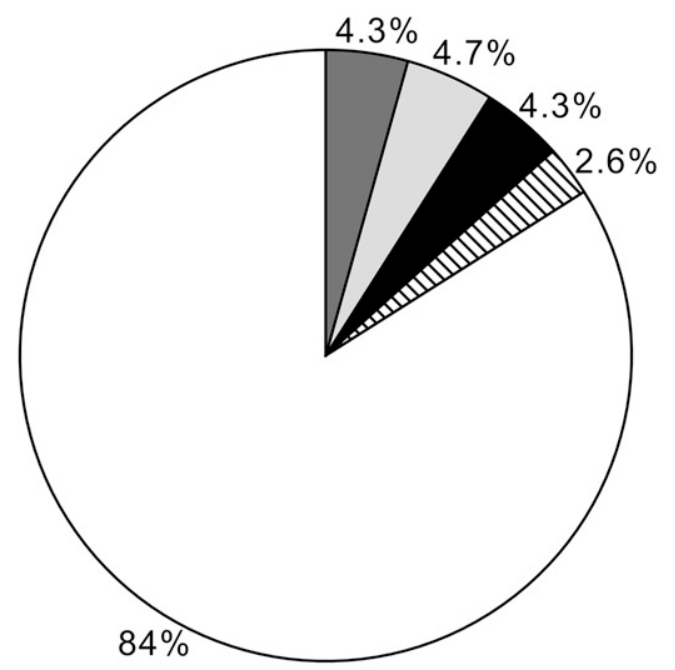

Fusarium species

F. verticillioides

F. fujikuroi

F. proliferatum

Other

Fig. 3. Fusarium species isolated from surface-sterilized Lygus lineolaris adults collected from cotton fields at the Tidewater Agricultural Research and Extension Center in Suffolk, Virginia, in A, $2018(n=50)$ and B, $2019(n=300)$. All samples were surface sterilized and plated on Fusarium-selective media. A, Fusarium isolates were identified based on translation elongation factor 1- $\alpha$ gene sequences. B, Fusarium isolates were identified using species-specific primers for Fusarium spp. that were associated with hardlock disease in 2018.
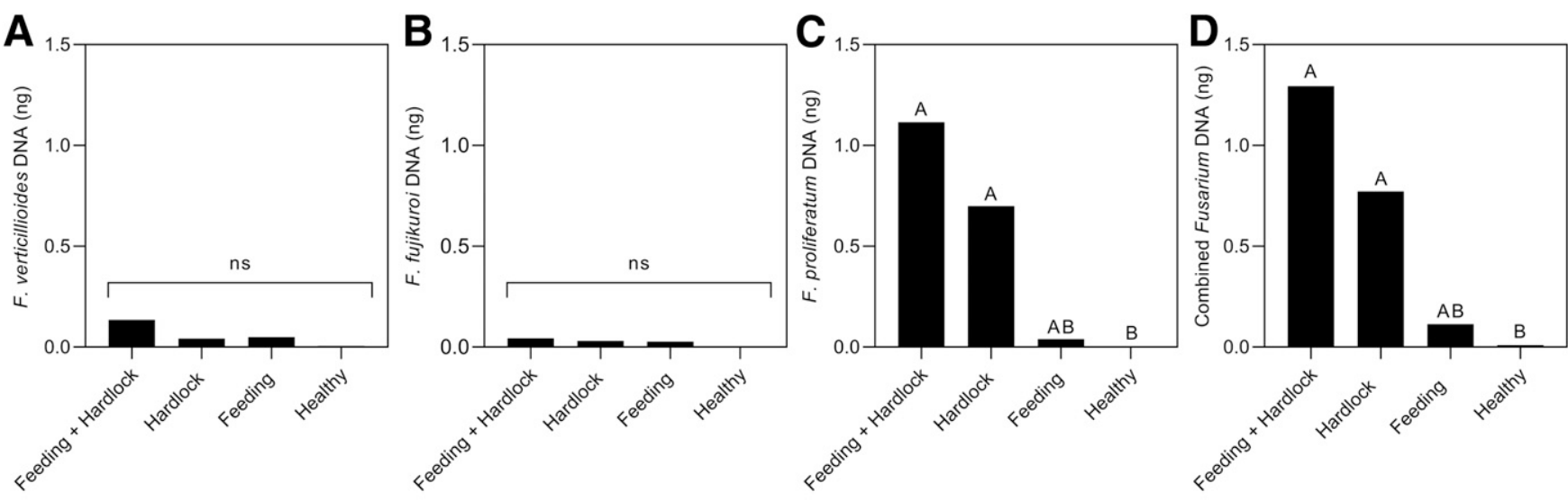

Observed symptoms

Fig. 4. Quantities of Fusarium spp. DNA in locules from cotton bolls collected at harvest at the Tidewater Agricultural Research and Extension Center in Suffolk, Virginia, in 2018 and 2019. Bolls were rated for Lygus lineolaris internal feeding symptoms (e.g., stained lint, warts, punctures) and hardlock presence. DNA in nanograms per locule for A, Fusarium verticillioides, B, F. fujikuroi, and C, F. proliferatum were quantified in each sample $(n=160)$ using respective species-specific primers. D, Combined Fusarium DNA in each sample was calculated by summing quantities of DNA for each individual species. Means denoted by the same letter were not different based on Tukey's honestly significant difference test $(P<0.05)$. ns, not significant. 
lineolaris infestations and subsequent boll injury increase the risk of hardlock in cotton. These results also agree with previous work linking flower thrips (Frankliniella spp.), another piercing-sucking insect that feeds on cotton during the flowering growth stage, with the occurrence of Fusarium hardlock (Mailhot et al. 2007). Thrips infest cotton flowers, and Fusarium species associated with hardlock disease (e.g., F. verticillioides) can infect flowers at anthesis (i.e., pollination) (Mailhot et al. 2007; Srivastava et al. 2010; Wright et al. 2003). L. lineolaris nymphs and adults also feed on flowers, in addition to squares and small bolls within a week of anthesis (Bariola 1969; Esquivel and Hinze 2019; Hanny et al. 1977; Layton 2000; Tugwell et al. 1976). L. lineolaris feeding on fruit at various growth stages and prolonged dabbing behavior to prepare plant tissues for digestion may facilitate fungal pathogen transmission and/or increase opportunities for pathogen entry during all reproductive stages of cotton development (Cline and Backus 2002).

The greatest amount of $F$. verticillioides infection (i.e., total DNA) found in cotton bolls harvested from the greenhouse experiment was in bolls mechanically punctured or exposed to L. lineolaris feeding and inoculated with $F$. verticillioides. Although these treatments did not differ from plants inoculated with $F$. verticillioides only, bolls exposed to both feeding injury and $F$. verticillioides were the only treatments that differed from untreated bolls. These results suggest that the probing behavior of piercing-sucking insects can increase the colonization of cotton bolls with Fusarium species, perhaps by providing greater opportunities for pathogens to invade and develop throughout the growing season (Bagga and Laster 1968; Esquivel 2015).

Sequenced DNA from fungal isolates within field-collected $L$. lineolaris adults also revealed the presence of two Fusarium species associated with hardlock disease, including $F$. verticillioides and $F$. proliferatum, as well as a closely related species, $F$. fujikuroi. All of these species fall within the Gibberella fujikuroi species complex and share similar morphological and phylogenetic characteristics (Leite et al. 2007; Marois and Wright 2004; Srivastava et al. 2010; Summerell 2019). L. lineolaris populations can migrate from nearby corn into surrounding cotton fields and may be preexposed to Fusarium species associated with these crops (Dorman et al. 2020; Jackson et al. 2014; Leslie and Summerell 2006). The Fusarium pathogen was isolated from $16 \%$ of surface-sterilized $L$. lineolaris adults collected in 2018 and $2019(n=350)$. These results, in addition to $L$. lineolaris migration patterns and flight capability, suggest that $L$. lineolaris may be responsible for low rates of Fusarium transmission in row-crop systems. However, further investigative research is needed to substantiate this claim.

Based on the quantities of Fusarium DNA detected, fieldcollected bolls with feeding and/or hardlock disease symptoms had significantly greater levels of colonization than healthy bolls. The greatest level of colonization detected in 2018 and 2019 was for $F$. proliferatum, followed by $F$. verticillioides and $F$. fujikuroi. Prior research has linked $F$. verticillioides and $F$. proliferatum with Fusarium hardlock disease (Leite et al. 2007; Marois and Wright 2004; Srivastava et al. 2010). Cotton bolls with hardlock symptoms had significantly greater colonization with $F$. proliferatum than healthy bolls. These results suggest that $F$. proliferatum primarily, but also $F$. verticillioides and $F$. fujikuroi, may play a role in Fusarium hardlock disease in this region, and L. lineolaris feeding can influence infection and colonization of cotton bolls with Fusarium spp.

L. lineolaris infestations have intensified in Virginia cotton since 2013, and small-plot research has shown considerable economic advantages (>\$300/ha) for appropriately managing L. lineolaris in Southeastern cotton when infestations are above economic thresholds (Aghaee et al. 2019). Although the proportion of hardlock in field plots managed with insecticides did not differ significantly from untreated plots, insecticide treatments targeting $L$. lineolaris lowered the total proportion of hardlocked locules by $10 \%$. Research by Marois et al. (2006) found that insecticide applications alone targeting thrips outbreaks in the early weeks of bloom reduced hardlock occurrence and increased yields, and there was no added benefit to using foliar fungicides. L. lineolaris is capable of feeding on cotton flowers and bolls during bloom, and infestations are capable of causing significant yield loss in cotton. Cotton yield loss from $L$. lineolaris injury may be exacerbated when economically damaging $L$. lineolaris infestations coincide with optimal environmental conditions for Fusarium pathogen development during bloom (e.g., high temperature and humidity). We encourage producers in this region to scout for L. lineolaris weekly during bloom and apply insecticides when economic thresholds are reached. Furthermore, research has shown that earlier planting dates, as well as early maturing varieties, reduce $L$. lineolaris injury and subsequent yield loss. Early maturing varieties may also reduce the amount of time cotton flowers and small bolls are susceptible to insect feeding as well as infection by fungal pathogens (when cotton is flowering) contributing to Fusarium hardlock development (Marois et al. 2007).

\section{Acknowledgments}

We thank Susan Petro, Sean Malone, and Matthew Wilkens for their assistance with fieldwork and greenhouse management. We also thank Timothy Bryant, Mary Silliman, Daniel Espinosa, Eli Hoar, and Kayla Babb for their assistance with data collection.

\section{Literature Cited}

Aghaee, M. A., Dorman, S. J., Taylor, S. V., and Reisig, D. D. 2019. Evaluating optimal spray timing, planting date, and current thresholds for Lygus lineolaris (Hemiptera: MiriOdae) in Virginia and North Carolina cotton. J. Econ. Entomol. 112:1207-1216.

Amatulli, M. T., Spadaro, D., Gullino, M. L., and Garibaldi, A. 2012. Conventional and real-time PCR for the identification of Fusarium fujikuroi and Fusarium proliferatum from diseased rice tissues and seeds. Eur. J. Plant Pathol. 134:401-408.

Bagga, H. S., and Laster, M. L. 1968. Relation of insects to the initiation and development of boll rot in cotton. J. Econ. Entomol. 61:1141-1142.

Bariola, L. A. 1969. The biology of the tarnished plant bug, Lygus lineolaris (Palisot de Beauvois), and its nature of damage and control on cotton. Ph.D. dissertation, Texas A\&M University, College Station, TX.

Bates, D. M., Maechler, M., Bolker, B., and Walker, S. 2015. Fitting linear mixedeffects models using lme4. J. Stat. Softw. 67:1-48.

Blinka, E. L., Herbert, A., Malone, S., Van Duyn, S. W., Roberts, P., Bradley, J. R., and Bacheler, J. S. 2010. Relationship between external stink bug (Hemiptera: Pentatomidae) boll-feeding symptoms and internal boll damage with respect to cotton lint gin-out and fiber quality. J. Econ. Entomol. 103:22362241.

Cline, A. R., and Backus, E. A. 2002. Correlations among AC electronic monitoring waveforms, body postures, and stylet penetration behaviors of Lygus hesperus (Hemiptera: Miridae). J. Econ. Entomol. 31:538-549.

Dorman, S. J., Schürch, R., Huseth, A. S., and Taylor, S. V. 2020. Landscape and climatic effects driving spatiotemporal abundance of Lygus lineolaris (Hemiptera: Miridae) in cotton agroecosystems. Agric. Ecosyst. Environ. 295:106910.

Esquivel, J. F. 2015. Stylet penetration estimates for a suite of phytophagous hemipteran pests of row crops. Environ. Entomol. 44:619-626.

Esquivel, J. F., and Hinze, L. L. 2019. The cotton boll: The relationship of species and genotype with temporal development of boll wall thickness. Crop Sci. 59: 1200-1210.

Fleischer, S. J., and Gaylor, M. J. 1988. Lygus lineolaris (Heteroptera: Miridae) population dynamics: Nymphal development, life tables, and Leslie matrices on selected weeds and cotton. Environ. Entomol. 17:246-253.

Frame, W. H., Herbert, D. A., Mehl, H., Cahoon, C., Reiter, M. S., and Flessner, M. 2016. Virginia Cotton Production Guide 2016. Virginia Cooperative Extension. https://www.sites.ext.vt.edu/newsletter-archive/cottonproduction-guide/2016.pdf

Hanny, B. W., Cleveland, T. C., and Meredith, W. R., Jr. 1977. Effects of tarnished plant bug, (Lygus lineolaris), infestations on presquaring cotton (Gossypium hirsutum). Environ. Entomol. 6:460-462.

Horn, T. O., Harris, F. A., Robbins, J. T., and Furr, R. E., Jr. 1999. Influence of boll age on susceptibility to tarnished plant bug injury. Pages 1044-1046 in: Proc. Beltwide Cotton Conf., National Cotton Council, Memphis, TN.

Jackson, R. E., Allen, K. C., Snodgrass, G. L., Krutz, L. J., Gore, J., Perera, O. P., Price, L. D., and Mullen, R. M. 2014. Influence of maize and pigweed on tarnished plant bug (Hemiptera: Miridae) populations infesting cotton. Southwest. Entomol. 39:391-399.

Lawrence, K., Hagan, A., Norton, R., Hu, J., Faske, T., Hutmacher, R., Mueller, J., Small, I., Grabau, Z., Kemerait, B., Price, P., Allen, T., Atwell, S., Idowu, J., Thiessen, L., Byrd, S., Goodson, J., Kelly, H., Wheeler, T., Isakeit, T., and Mehl, H. L. 2019. Cotton disease loss estimate committee report. Pages 54-56 in: Proc. Beltwide Cotton Conf., National Cotton Council, Memphis, TN

Layton, M. B. 2000. Biology and damage of the tarnished plant bug, Lygus lineolaris, in cotton. Southwest. Entomol. 23:7-20. 
Leite, B., Wright, D., and Marois, J. 2007. Development of Fusarium in cotton bolls: Greenhouse and field results. Pages 759-762 in: Proc. Beltwide Cotton Conf., National Cotton Council, Memphis, TN.

Lenth, R. 2018. emmeans: Estimated marginal means, aka least-squares means. $\mathrm{R}$ package version 1.2.4. https://cran.r-project.org/web/packages/emmeans/index. html

Leslie, J., and Summerell, B. 2006. The Fusarium laboratory manual. Blackwell Publishing, Ames, IA,

Liu, S., and Bonning, B. C. 2019. The principal salivary gland is the primary source of digestive enzymes in the saliva of the brown marmorated stink bug, Halyomorpha halys. Front. Physiol. 10:1255.

Mailhot, D. J., Marois, J. J., and Wright, D. L. 2007. Influence of flower thrips on Fusarium hardlock severity. Plant Dis. 91:1423-1429.

Marois, J. J., Mailhot, D. J., Wright, D. L., and Wiatrak, P. J. 2006. Application of pesticides to control Fusarium hardlock of cotton in Florida. Pages 121-125 in: Proc. Beltwide Cotton Conf., National Cotton Council, Memphis, TN.

Marois, J. J., and Wright, D. L. 2004. Etiology, epidemiology, and control of Fusarium hardlock of cotton in the Southeast: The possibilities. Pages 331-336 in: Proc. Beltwide Cotton Conf., National Cotton Council, Memphis, TN.

Marois, J. J., Wright, D. L., Leite, B., Mailhot, D. J., and Osekre, E. 2007. Hardlock of cotton: Historical review and perspectives. In: Proc. World Cotton Res. Conf, 10-14 September 2007, Lubbock, TX. http://wcrc.confex.com/wcrc/2007/ techprogram/P1837.HTM.

Marois, J. J., Wright, D. L., and Wiatrak, P. J. 2002. Association of Fusarium sp. with hardlock of cotton in the Southeastern U.S. In: Proc. Beltwide Cotton Conf., National Cotton Council, Memphis, TN. http://www.cotton.org/beltwide/ proceedings/getPDF.cfm?year=2002\&paper=C017.pdf.

Mitchell, P. L. 2004. Heteroptera as vectors of plant pathogens. Neotrop. Entomol. 33:519-545.

Mulè, G., Susca, A., Stea, G., and Moretti, A. 2004. Specific detection of the toxigenic species Fusarium proliferatum and $F$. oxysporum from asparagus plants using primers based on calmodulin gene sequences. FEMS Microbiol. Lett. 230:235-240.

Musser, F., Stewart, S., Bagwell, R., Lorenz, G., Catchot, A., Burris, E., Cook, D., Robbins, J., Greene, J., Studebaker, G., and Gore, J. 2007. Comparison of direct and indirect sampling methods for tarnished plant bug (Hemiptera: Miridae) in flowering cotton. J. Econ. Entomol. 100:1916-1923.

O’Donnell, K., Kistler, H. C., Cigelnik, E., and Ploetz, R. C. 1998. Multiple evolutionary origins of the fungus causing Panama disease of banana: Concordant evidence from nuclear and mitochondrial gene genealogies. Proc. Natl. Acad. Sci. U.S.A. 95:2044-2049.

Opoku, J., Kleczewski, N. M., Hamby, K. A., Herbert, D. A., Malone, S., and Mehl, H. L. 2019. Relationship between invasive brown marmorated stink bug (Halyomorpha halys) and fumonisin contamination of field corn in the Mid-Atlantic U.S. Plant Dis. 103:1189-1195.

Schmale, D. G., Leslie, J. F., Saleh, A. A., Shields, E. J., and Bergstrom, G. C. 2006. Genetic structure of atmospheric populations of Gibberella zeae. Phytopathology 96:1021-1026.
Seifert, K. A., Aoki, T., Baayen, R. P., Brayford, D., Burgess, L. W., Chulze, S., Gams, W., Geiser, D., de Gruyter, J., Leslie, J. F., Logrieco, A., Marasas, W. F. O., Nirenberg, H. I., O'Donnell, K., Rheeder, J., Samuels, G. J., Summerell, B. A., Thrane, U., and Waalwijk, C. 2003. The name Fusarium moniliforme should no longer be used. Mycol. Res. 107:643-644.

Sempere, F., and Santamarina, M. P. 2009. The conidia formation of several Fusarium species. Ann. Microbiol. 59:663-674.

Snodgrass, G. L. 1996. Insecticide resistance in field populations of the tarnished plant bug (Heteroptera: Miridae) in cotton in the Mississippi Delta. J. Econ. Entomol. 89:783-790

Snodgrass, G. L., Scott, W. P., and Smith, J. W. 1984. Host plants and seasonal distribution of the tarnished plant bug (Hemiptera: Miridae) in the delta of Arkansas, Louisiana, and Mississippi. Environ. Entomol. 13:110-116.

Srivastava, P., Maihot, D. J., Leite, B., Marois, J. J., Wright, D. L., and Nichols, R. L. 2010. Fusarium verticillioides (Saccardo) Nirenberg associated with hardlock of cotton. Curr. Microbiol. 61:79-84.

Stewart, S. D., and Gaylor, M. J. 1994. Effects of age, sex, and reproductive status on flight by the tarnished plant bug (Heteroptera: Miridae). Popul. Ecol. 23: 80-84.

Summerell, B. A. 2019. Resolving Fusarium: Current status of the genus. Annu. Rev. Phytopathol. 57:323-339.

Tugwell, P., Young, S. C., Jr., Dumas, B. A., and Phillips, J. R. 1976. Plant bugs in cotton: Importance of infestation time, types of cotton injury, and significance of wild hosts near cotton. Univ. of Ark. Agric. Exp. Stn. Bull. Rep. Ser. 227: $1-24$.

Williams, M. R. 2014. Cotton insect loss estimates. Pages 798-812 in: Proc. Beltwide Cotton Conf., National Cotton Council, Memphis, TN.

Williams, M. R. 2017. Cotton insect loss estimates. Pages 710-754 in: Proc. Beltwide Cotton Conf., National Cotton Council, Memphis, TN.

Willrich, M. M., Leonard, B. R., Padgett, B. G., and Lamotte, L. R. 2004. Boll injury and yield losses in cotton associated with brown stink bug (Heteroptera: Pentatomidae) during flowering. J. Econ. Entomol. 97: 1928-1934.

Wood, W., Gore, J., Catchot, A., Cook, D., Dodds, D., and Krutz, L. J. 2016 Susceptibility of flowering cotton to damage and yield loss from tarnished plant bug (Hemiptera: Miridae). J. Econ. Entomol. 109:1188-1195.

Wright, D. L., Marois, J. J., Vargas, M. A., and Wiatrak, P. J. 2003. Management of hardlock in cotton in the Southeast. Pages 2076-2080 in: Proc. Beltwide Cotton Conf., National Cotton Council, Memphis, TN.

Wright, D. L., Marois, J. J., Wiatrack, P. J., and Katsvairo, T. 2004. History and overview of the hardlock problem in humid areas of the Deep South. Pages 328-330 in: Proc. Beltwide Cotton Conf., National Cotton Council, Memphis, TN.

Yates, I. E., and Jaworski, A. J. 2000. Differential growth of Fusarium moniliforme relative to tissues from 'Silver Queen', a sweet maize. Can. J. Bot. 78:472-480.

Young, O. P. 1986. Host plants of the tarnished plant bug, Lygus lineolaris (Heteroptera: Miridae). Ann. Entomol. Soc. Am. 79:747-762. 